\title{
Qualitative analysis of refractive errors in school children
}

\author{
Priyadarshani Patil Cholera ${ }^{1}$, Kshitij S. Tamboli ${ }^{2}$, Nupur Chakravarty ${ }^{3, *}$ \\ ${ }^{\mathbf{1}}$ Associate Professor, ${ }^{2}$ Junior Resident, ${ }^{3}$ Professor, Dept. of Ophthalmology, Dr. D. Y. Patil Medical College, Navi Mumbai, \\ Maharashtra, India
}

*Corresponding Author:

Email: nupur59@gmail.com

\begin{abstract}
Purpose: To study the refractive errors and its implication on the quality of life; among the children in the semi urban population.

Materials and Methods: This prospective, cross-sectional study was conducted among the 500 children (5-15 years), over a period of 6 months.

Observations: All patients examined for unaided visual acuity using snellens chart. After visual acuity, subjected to dilated retinoscopy and fundoscopy.

Conclusions: It was concluded that clear need to have regular and simple vision testing of children of school going age, so as to detect visual abnormalities at an earlier stage thereby preventing long term visual disabilities. Regular school health programs regarding visual acuity improves scholastic performance of children.
\end{abstract}

Keywords: Refractive errors, School children, Semi-urban population.

\section{Introduction}

Formative years in a student's life are most important. These years determine one's physical, intellectual and behavioral pattern. Any problem in vision during formative years can hamper the intellectual development, maturity and performance of a person in future life. ${ }^{1}$ Childhood visual impairment due to uncorrected refractive errors is one of the most common problems in school-age in children. It is the second leading cause of blindness. Even though cataract which is the leading cause of blindness, refractive error accounts for twice the number of blindperson-due to cataract. ${ }^{2}$ Uncorrected refractive errors are responsible for up to $42 \%$ of the cases of visual impairment worldwide and remain prevalent even in high income countries and have significant economic implications in terms of potential loss of productivity.

A paper published on 2 Aug 2017 in the Lancet estimates that there were 36 million people who were blind. Further, 217 million people live with severe or moderate visual impairment (MSVI). In total, 253 million people were living with visual impairment in 2015. It also estimates that 1.1 billion people have nearvision impairment condition that can be corrected with spectacles. ${ }^{3}$

Data over the last 25 years shows that there has been significant progress in preventing and curing vision impairment in many countries. An estimated 253 million people live with vision impairment: 36 million are blind and 217 million have moderate to severe vision impairment. $81 \%$ of people who are blind or have moderate or severe vision impairment are aged 50 years and above. Globally, chronic eye diseases are the main cause of vision loss. Uncorrected refractive errors and then un-operated cataract are the top two cause of vision impairment. Un-operated cataract remains the leading cause of blindness in low and middle-income countries. The prevalence of infectious eye diseases, such as trachoma and onchocerciasis, have reduced significantly over the last 25 years. 3 Approximately 19 million children are vision impaired, of these, 12 million children have a vision impairment due to refractive error. Around 1.4 million have irreversible blindness, requiring access to vision rehabilitation to optimize functioning and reduce disability. Over $80 \%$ of all vision impairment can be prevented or cured. ${ }^{4}$

Because of the increasing realization of the enormous need for correction of refractive errors worldwide, this condition has been considered one of the priorities of "Vision 2020 -The Right to Sight", a global initiative launched by a coalition of nongovernment organizations and the World Health Organization. ${ }^{5,6}$ Motive of this initiative to eliminate avoidable visual impairment and blindness on a global scale. Diagnosis and treatment of refractive error is relatively simple and is one of the easiest ways to reduce impaired vision. Despite all possible precautions refractive error is the second most major cause of patient's pool to ophthalmologists in India. The different age group of children has different problems and needs as explained in table no. $1^{7}$

In a study in Uttarakhand state, study conducted by GVS Murthy stated that $18(0.6 \%)$ students suffered from amblyopia. Amblyopia treatment is most effective when done early in the child's life, usually before the age of seven. ${ }^{8}$ School screening is the best way to detect amblyopia in school children. Thus, screening of school children can play an important part in detecting refractive errors. Early detection can prevent deterioration of refractive and prevent the development of amblyopia. Aim of present work was to determine 
the prevalence of refractive errors among the children and to study the sociodemographic characteristics associated with the refractive errors. ${ }^{5}$

\section{Materials and Methods}

Present Study was cross-sectional prospective study conducted on 500 population in 5-15 years age group for 6 months durations. Inclusion criteria were patients with refractive errors in 5-15 years ages and those children with eye injuries, eye diseases that affected visual functions (corneal opacities, cataracts, fundus pathology) and children who were allergic to mydriatic and with neurological impairment, spastic paralysis, seizure disorders, etc. were excluded.

Recruitment of patients was initiated after ethics committee approval. Procedure and purpose of study explained to patients and informed consent as well ascent taken form the guardian/parents. All patients examined for unaided visual acuity using Snellens chart. After visual acuity, subjects dilated retinoscopy and fundoscopy followed by post mydriatic test on follow-up.

\section{Results and Discussion}

In this study it was found that age of patients is $10.0+/-2.95$. Strict adhered to inclusion and exclusion criteria we examined $48.8 \%$ male (244) and $51.2 \%$ female (256) patients. During the examinations we noticed major complaints like headache (160), GPD OV (137), watering of eye/s (73), redness of eye/s (26) and pain (19). Types of refractive errors and their distribution were normal (333), Myopia (113), Myopic astigmatism (29), Mixed astigmatism (18) and Hypermetropia (7). Percentage analysis of refractive errors was shown in table 2 . We have noted family history and found that 150 parents of school going children are having history of refractive errors.

\section{Discussion}

A study was conducted by Batra et al stated that a total of 19,610 students were examined over 3 years (2003-2005) of these 11,200 were males and 8,410 were females. There were 8,834 students in the 510 years age group and 10,776 in the $11-$ 15 years age groups. The number of students who had decreased vision (defined as distant visual acuity of 6/9 or less) was 2,485 . Of these, there was a total of 1,366 myopes; 748 hyperopes; 284 with astigmatism and 87 amblyopic children (64 unilateral; 23 bilateral). So percentagewise numbers reported by Batra et al was almost similar what we observed in this study. ${ }^{9}$

In our study we found that myopia was the commonest refractive error accounting to $22.6 \%$ of the total followed by astigmatism followed by hypermetrapia. Similar results were found according to the study done by Das A et al. (2007) reported that out of the total 2317 students in the age group of 7-15 years, 53 were suffering from refractive errors. Myopia was the most common (14\% of the total). It also became more common in the older age group that is 915 years of age. ${ }^{10}$ A study done in New Delhi also concluded that myopia was the most common refractive error among school children followed by astigmatism and hypermetropia. ${ }^{11}$ A study done by Mehzabeen Rahman et al form Assam Medical College and Hospital Dibrugarh showed that $8.8 \%$ of the study population had refractive error, boys $(51 \%)$ more than girls (49\%). Myopia (7.17\%) was the most common refractive error followed by astigmatism $(2.17 \%)$ and hypermetropia $(1.50 \%) .^{12}$

Jyotsna Sharma et al examined total of 1000 students between 6-16 years age groups for refractive errors, where male to female ratio was 0.97:1. Ocular morbidity was detected in $290(29 \%)$ ocular disorders. Out of 1000 students 246 had refractive error, the most common ocular morbidity which accounted to $24.6 \%$ of the total was ref error and uncorrected ref error was in $17.7 \%$, followed by $2.7 \%$ squint cases, 1.7 $\%$ of color vision defective cases.

In all referred studies observations reported are more or less similar from our study. ${ }^{13}$ In this study we found that hypermetropia was the least common refractive error.

Table 1: Types of refractive errors according to the age:

\begin{tabular}{|l|c|}
\hline Age group & Specific needs: \\
\hline $\begin{array}{l}\text { Preschool }(<6 \\
\text { years })\end{array}$ & $\begin{array}{c}\text { Significant refractive errors are } \\
\text { uncommon }\end{array}$ \\
\hline $\begin{array}{l}\text { Early school } \\
(6-11 \text { years })\end{array}$ & $\begin{array}{c}\text { Untreated and undetected refractive } \\
\text { error, eye disease and strabismus can } \\
\text { lead to amblyopia. }\end{array}$ \\
\hline $\begin{array}{l}\text { Late school } \\
(>11 \text { years) }\end{array}$ & $\begin{array}{c}\text { Myopia progresses and then stabilizes } \\
\text { Undetected refractive errors present at } \\
\text { younger age are still present. }\end{array}$ \\
\hline
\end{tabular}

Table 2: Types of refractive errors and their distribution:

\begin{tabular}{|l|c|c|}
\hline $\begin{array}{l}\text { Type of Refractive } \\
\text { error }\end{array}$ & $\begin{array}{c}\text { Number of } \\
\text { Cases }\end{array}$ & Percentage \\
\hline Normal & 333 & $66.6 \%$ \\
\hline Myopia & 113 & $22.6 \%$ \\
\hline Hypermetropia & 07 & $1.4 \%$ \\
\hline Myopic astigmatism & 29 & $5.8 \%$ \\
\hline Mixed astigmatism & 18 & $3.6 \%$ \\
\hline
\end{tabular}

\section{Conclusion}

The present study reveals considerable prevalence rates of refractive errors and the need for their correction among children aged 5 to 15 years even in the semi urban population. Regular and simple vision testing of children of school going age is need of time to correct visual abnormalities at an earlier stage and prevent long term visual disabilities. 


\section{References}

1. W.H.O Report. Data on Blindness throughout the World. W.H.O Chronicle 1979;33(718):275.

2. Dandona R, Dandona L, Naduvillath S, Srinivas M, McCarthy CA, Rao GN. Refractive errors in an urban population in Southern India: The Andhra Pradesh Eye Disease Study. Invest Ophthalmol Vis Sci 1999;40:28108.

3. Rupert R A Bourne, Seth R Flaxman, Tasanee Braithwaite, Maria V Cicinelli, Aditi Das, Jost B Jonas, et al. Magnitude, temporal trends, and projections of the global prevalence of blindness and distance and near vision impairment: a systematic review and metaanalysis. The Lancet Global Health. 2017;5(9):888-e89.

4. Silvio P. Mariot. Global data on visual impairments 2010. World Health Organization, 20 Avenue Appia, 1211 Geneva 27, Switzerland.

5. G V S Murthy. Vision Testing for Refractive Errors in Schools 'Screening' Programmes in Schools. Community Eye Health. 2000;13(33):3-5.

6. Pararajasegaram R. VISION 2020 - The Right to Sight: from strategies to action. Am J Ophthalmol 1999;128:359-60.

7. Thylefors B. A global initiative for the elimination of avoidable blindness [editorial]. American Journal of Ophthalmology 1998;125:90-3.

8. Tarannum Shakeel, Sanjeev Kumar Mittal. Pattern of Refractive Errors in Primary School Children in Dehradun City of Uttrakhand State. Del J Ophthalmol Vol 27 No: 2 October-December 2016.

9. Nitin Batra, Dr. Dhawal Kaushal, Dr. Amitoj singh Gill. Refractive error in school children: A review from Punjab.2007;1(4);1-7.

10. Das A, Dutta H, Bhaduri G, De Sarkar A, Sarkar K, Bannerjee M. A study on refractive errors among school children in Kolkata; J Indian Med Assoc.2007 April;105(4):169-72.

11. Matta S, Matta P, Gupta V, Dev A. Refractive errors among adolescents attending Ophthalmic OPD. Ind Joun Comm Medicine 2006-04-2005-06;31(2).

12. Mehzabeen Rahman, Bhanu Devi, J.J. Kuli, Gourangie Gogoi. A Study on the Refractive Status of School Going Children Aged Between 10 to 15 Years in Dibrugarh Town, Assam, India. IOSR Journal of Dental and Medical Sciences. 2015;14(2 Ver. III):27-33.

13. Jyotsna Sharma, Dhawal Agrawal, Malhar Vyas, Parul Hans and Juhi Garg. Prevalence of refractive error, squint and color vision defects among school children in Rajiv International School, Mathura. International Journal of Current Research. 2017;9(11):61595-61598. 